\title{
Sulphasalazine-induced cerebral lupus erythematosus
}

\author{
P. RAFFERTY \\ M.R.C.P.
}

\author{
A. C. Young \\ M.R.C.P.
}

\author{
M. R. HAENEY \\ M.R.C.P., M.R.C.Path. \\ Department of Neurology, Salford Royal Hospital, Salford
}

\begin{abstract}
Summary
A 19-year-old girl with ulcerative colitis presented in coma. Subsequent investigation showed this to be due to sulphasalazine-induced cerebral lupus erythematosus.
\end{abstract}

\section{Introduction}

Sulphasalazine-induced systemic lupus erythematosus has been reported in $\mathbf{8}$ previous cases (AlarconSegovia et al., 1965; Griffiths and Kane, 1977; Jaup, 1978; Crisp and Hoffbrand, 1980). None of these cases has exhibited signs of neurological involvement. In this case, severe cerebral disease appeared to be the main manifestation of drug-induced lupus.

\section{Case report}

In November 1980, a 19-year-old girl presented with a 5-day history of right frontal headache and a 3-day history of deteriorating conscious level. Three years earlier, she had been diagnosed as having ulcerative colitis on clinical, radiological and sigmoidoscopic criteria, and had been treated with sulphasalazine, $1.5 \mathrm{~g}$ daily. There was no family history of ulcerative colitis or connective tissue disease.

On examination, she was apyrexial but anaemic; there was no neck stiffness or evidence of skin or joint involvement. She did not speak or obey commands. Although she moved all 4 limbs to painful stimuli, there was less response on the right side. There was no reflex asymmetry but both plantar responses were extensor. Initially, fundoscopy was normal but she developed transient bilateral papilloedema during the first week of her illness.

Initial investigations showed a haemoglobin of $7.6 \mathrm{~g} / \mathrm{dl}$, a hypochromic, microcytic blood film and a white count of $9.3 \times 10^{9} / 1$, with a normal differential count. The erythrocyte sedimentation rate was raised at $52 \mathrm{~mm}$ in the first hour. Plasma urea, electrolytes and liver enzymes were normal. Com puterized axial tomography (CT) brain scan showed evidence of diffuse low density in the region of both $\infty$ basal ganglia. Electroencephalogram (EEG) showed a right temporal delta focus of high amplitude but, $\rightarrow$ on arousal, there developed diffuse delta activity. TR Cerebrospinal fluid (CSF) examination showed a 을 raised protein level $(4 \cdot 7 \mathrm{~g} / \mathrm{dl})$, with a normal glucose content $(3.2 \mathrm{mmol} / \mathrm{l})$ and a white cell count of $<1.0 \times 10^{9} / 1$.

In view of the possibility of acute viral encephalitis treatment was started with dexamethasone, $30 \mathrm{rrg}$ daily, and acyclovir, $500 \mathrm{mg}$ 8-hourly via i. v. infusion. However, a right frontal brain biopsy showed no evidence of viral infection, vasculitis or tumour and further viral studies on brain tissue, CSF and $\stackrel{\odot}{\mathcal{Q}}$ serum were all negative.

Over the following 10 days, her conscious level $\overrightarrow{\overrightarrow{0}}$ began to improve and she was later able to move her right arm in response to commands. She developed a left homonymous hemianopia and spasticity in both arms and legs. Acyclovir was stopped after을 10 days and steroids were gradually reduced. $A$ repeat CT scan showed evidence of diffuse low 3 density throughout the right hemisphere with moderate ventricular enlargement, compatible with $\frac{\circ}{\xi}$ cerebral infarction.

No further sulphasalazine was given after ad- $\stackrel{ }{2}$ mission to hospital because of the possibility of a $\frac{7}{0}$ drug-induced lupus syndrome. Immunological investigations 2 weeks after admission showed (normal $N_{\sigma}$ ranges in brackets): Antinuclear antibody (IgG) was positive-1560 u./ml. Anti-DNA antibody $\mathcal{N}^{-}$ (Crithidia luciliae, immunofluorescence) was negative $\mathrm{\omega}$

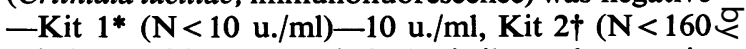
$\mathrm{u} . / \mathrm{ml}$ )—positive, $750 \mathrm{u} . / \mathrm{ml}$. Anti-ribonucleoprotein $\stackrel{0}{\mathrm{C}}$ antibody was negative. Circulating immune complexes, platelet aggregation titre $(1 / 20)$ was positive -

* Radiochemical Centre, Amersham, England.

† Cordis Laboratories, Florida, U.S.A. 
1/160. Complement- $\mathrm{CH}_{50}(24-45 \mathrm{u} . / \mathrm{ml})-17 \mathrm{u} . / \mathrm{ml}$; Clq $(80-120 \%$ serum pool $)-80 \%$; C4 $(0.2-0.4 \mathrm{~g} / 1)$ $-0.2 \mathrm{~g} / 1$; C3 $(0.8-1.4 \mathrm{~g} / \mathrm{l})-0.9 \mathrm{~g} / \mathrm{l}$. Most of the abnormalities regressed over the next 3 months. In addition, serial immunoglobulin levels remained consistently within the normal range. Direct immunofluorescent examination of a biopsy of clinically normal skin, taken 10 weeks after admission, showed mild deposition of C3, but not immunoglobulin, in a granular distribution along the dermo-epidermal junction. The CSF returned to normal. Further tests showed her to be of the slowacetylator phenotype and her HLA type was found to be A2A3B7.

Three months after admission to hospital, the patient developed bloody diarrhoea (acute phase ulcerative colitis on biopsy) and was treated with prednisolone enemas and oral prednisolone. She later required colectomy.

\section{Discussion}

This patient showed some clinical and immunological features of an acute lupus syndrome, although not fulfilling the American Rheumatism Association's criteria for the diagnosis of systemic lupus erythematosus (SLE) (Cohen et al., 1971). However, antinuclear antibodies and circulating immune complexes were present, with activation of the classical pathway of complement. The minor degree of abnormality found may be due to the combined effects of withdrawal of sulphasalazine, the introduction of dexamethasone therapy and the time-lag before blood was taken for testing. Surprisingly, measurement of DNA antibody activity using 2 commercial kits gave discrepant results. This may be because kit 2 detects antibodies to both single- and double-stranded DNA and therefore suggests that circulating antibodies to single-stranded DNA predominated in this patient. Over a 3-month period, most of the immunological abnormalities had regressed. Again, this was probably due to a combination of withdrawal of sulphasalazine and the introduction of prednisolone to control her colitis.

Sulphasalazine-induced lupus has been previously reported and some authors have been able to demonstrate the reappearance of symptoms and signs of SLE following repeat challenge of their patients with sulphasalazine (Griffiths and Kane, 1977; Jaup, 1978). In view of the severity of this patient's disability, the authors did not consider this to be justified. Patients ingesting sulphasalazine who are of the slow-acetylator phenotype have been shown to develop higher serum concentrations of sulphapyridine (Das et al., 1973). Where acetylation status has been tested, patients with sulphasalazineinduced lupus have been of this phenotype (Griffiths and Kane, 1977; Jaup, 1978). All previously reported cases have exhibited mainly arthralgia, polyserositis and dermatological features, none has shown features of neurological improvement. This is perhaps surprising since most series of SLE now report some neurological involvement in $50-70 \%$ of patients.

This case highlights that severe cerebral disease may be the major manifestation of a drug-induced SLE syndrome. Recognition of this complication and its management may be extremely difficult.

\section{References}

Alarcon-Segovia, D., Herskovic, T., Dearino, W.H. Bartholomew, L.G., Cain, J.C. \& Shurer, R.C. (1965) Lupus erythematosus cell phenomenon in patients with chronic ulcerative colitis. Gut, 6, 39.

Cohen, S.A., Reynolds, W.E., Franklin, F.C., Kulka, J.P., Ropes, M.W., Shulman, L.E. \& Wallace, S.L. (1971) Preliminary criteria for the classification of systemic lupus erythematosus. Bulletin of Rheumatic Diseases, 21, 643.

CRISP, A.J. \& HofFrRAND, B.I. (1980) Sulphasalazine-induced systemic lupus erythematosus in a patient with Sjögren's syndrome. Journal of the Royal Society of Medicine, 73, 60.

Das, K.M., Eastwood, M.A., McManus, J.P.A. \& Sircus, W. (1973) The metabolism of salicylazo-sulphapyridine in ulcerative colitis; 1 . The relationship between metabolites and the response to treatment in inpatients. Gut, 14, 631 .

GriffithS, I.D. \& KANE, S.P. (1977) Sulphasalazine-induced lupus syndrome in ulcerative colitis. British Medical Journal, 2, 1188.

Hughes, G.R.V. (1980) Central nervous system lupusdiagnosis and treatment. Journal of Rheumatology, 7, 405.

JAUP, B.H. (1978) Salazosulfapyridin-induxiertes Lupus erythematodes Syndrom bei Colitis ulcerosa. Deutsche medizinische Wochenschrift, 103, 1211. 